\title{
Influence of Agricultural Mechanization Development on Agricultural Green Transformation in Western China, Based on the ML Index and Spatial Panel Model
}

\author{
Xiaoming Guo, Sen Huang $(\mathbb{D}$, and Yu Wang \\ Research Center of National Economy and International Business, Sichuan International Studies University, Chongqing 400031, \\ China \\ Correspondence should be addressed to Sen Huang; mikerwashine@163.com
}

Received 21 March 2020; Revised 18 May 2020; Accepted 25 July 2020; Published 24 August 2020

Academic Editor: Luis M. López-Ochoa

Copyright ( 92020 Xiaoming Guo et al. This is an open access article distributed under the Creative Commons Attribution License, which permits unrestricted use, distribution, and reproduction in any medium, provided the original work is properly cited.

The agricultural mechanization development can promote the high-quality development of agriculture, but the agriculture which faces the huge environmental pressure also needs to transform to the green sustainable development. Based on agricultural panel data of 30 provinces in China from the year 2008 to 2017, this paper measures the level of agricultural green transformation using the Malmquist-Luenberger (ML) index. Furthermore, the spatial panel econometric model is used to empirically investigate the impact of agricultural mechanization development on this green transformation. It concludes that the agricultural green transformation in western China shows an upward trend in fluctuations, with its overall transformation level still lower than the national average level. Besides, the agricultural mechanization operation level in the western region has a positive role in promoting the green transformation of agriculture, while the agricultural mechanization equipment level shows the opposite force. Compared with southwest China, the agricultural mechanization operation level in northwest China has a more positive impact. The improvement of farmers' income and agricultural technology has positive impacts on agriculture green transformation in the whole western region, while agricultural human capital shows an opposite impact on the northwest and southwest.

\section{Introduction}

In the recent years, China has attached huge importance on the Rural Revitalization Strategy put forward in the 19th National Congress of the Communist Party of China. The rural revitalization cannot be separated from the development of agricultural modernization, and the realization of agricultural modernization depends on the assistance of various agricultural machines for agricultural production [1]. Since the reform and opening up, China's agricultural machinery industry has started to develop rapidly. In 2004, China issued the law of the People's Republic of China on the promotion of agricultural mechanization, which helped to form the development peak of agricultural machinery. In 2012, China's total power of agricultural machinery reached 1 billion kilowatts and, later, remained the growth. China in the year 2017 is maintaining the status of the world's largest agricultural machinery producer. The development of agricultural machinery has played an important and positive role in the improvement of China's agricultural comprehensive production capacity, the growth of farmers' income, and the prosperity of rural areas. Therefore, agricultural machinery is more and more popular with agricultural producers. In addition, China has strengthened subsidies and other support measures for agricultural machinery. As a result, various agricultural machines are commonly used in the production of crops, such as ploughing, planting, and harvesting [2]. In 2017, China's comprehensive mechanization rate of crop in the process of ploughing, planting, and harvesting has exceeded $66 \%$.

However, there is a great regional imbalance in the development of agricultural mechanization in China [3]. In the western rural areas, the agricultural development is relatively backward, accompanied by drought, water 
shortage, and complex geology, and its level of agricultural mechanization development is far lower than that in the middle and eastern areas. For example, in the year 2017, western China, occupying about $70 \%$ of the whole nation's land, consumed a total 266 million kilowatt power of agricultural machinery, while other areas in China consumed a total of 717 million kilowatt. Also, for the number of specific agricultural machines, western China, in this year, used only 2 million large and medium tractors, while the other areas used 4.3 million. Therefore, the potential for agricultural machinery demand in the western areas is even higher than that in the eastern areas, and the promotion of agricultural mechanization in the western areas is of greater significance than that in the eastern areas, for the benefits of agriculture modernization, poverty alleviation, and rural revitalization in western China.

At the same time, it cannot be ignored that the problems of resources and environment faced by China's agricultural development are very prominent, especially in the western rural areas where the natural ecosystem is relatively fragile [4]. In western China, the bearing capacity of cultivated land is low, and the environmental capacity is very limited. Under this background, the agricultural production mode in western China is still relatively extensive. Namely, on one hand, the agricultural production relies heavily on a large number of inputs from fertilizers, pesticides, energy, and other chemicals. On the other hand, there is also low utilization rate of agricultural production resources. The loss rate of fertilizer and pesticide is very high. Lots of agricultural film residual stays in the soil. Also, the untreated livestock and poultry excrement is discharged into the water. All these things have caused a lot of nonpoint source pollution and exerted great pressure on the fragile water and soil resources in the western rural areas. Therefore, the sustainable development of China's agriculture in the western rural areas is disappointing, and it is urgent for China's western agriculture to realize the green transformation.

In this context, pushing forward the development of China's western agricultural mechanization can effectively improve the efficiency of agricultural production, but it also would lead to more energy consumption and environmental pollution because the vigorous development of agricultural mechanization needs to consume more gasoline and diesel, which results in greater energy consumption compared with traditional agricultural production. In some circumstances, those old agricultural machinery products with high energy consumption are not eliminated in time in the western rural areas, causing excessive energy consumption and more harmful exhaust emissions, all of which have brought negative environmental pollution problems in the western rural areas.

Therefore, this paper attempts to measure the current level of agricultural green transformation in western China and sort out the factors impacting the agricultural green transformation development including the agricultural mechanization, in order to provide more targeted policy recommendations for the future sustainable development of agricultural modernization in western China and also offer reference for the overall green transformation in China.
The remainder of this paper is arranged as follows. Section 2 reviews the literature related to the research subject. Section 3 tries to measure the agricultural green transformation in western China by adopting the Malmquist-Luenberger (ML) index. Section 4 employs the spatial econometric model to verify the influence of agricultural mechanization on green transformation in western China. The final section draws conclusions and provides some policy suggestions.

\section{Literature Review}

The green transformation of agriculture refers to the transformation of agriculture from a traditional development mode relying on chemical fertilizers, pesticides, and energy input to a green, efficient, and sustainable development mode. Deng et al. [5] put forward the importance of green agriculture on China's sustainable development. $\mathrm{Hu}$ and Tian [6] discussed the meaning and characteristics of agricultural green transformation. Wang [7], Yu $[8,9]$, Zhao [10], and others also called for the urgent need for Chinese agriculture to change its production mode as soon as possible, believing that the new agricultural modernization must make more economical use of resources and energy and strengthen environmental protection, and the process of agricultural green transformation and upgrading cannot be achieved without the guidance of the concept of green development. Tan [11] confirmed the arrival of the green agricultural transformation era and briefly analyzed the main factors restricting the agricultural green transformation in China. Li and Chen [12] discussed the transformation path of green agriculture in Fujian province, China, from five agricultural chains, including the production base, production process, processing mode, circulation consumption, and function expansion. However, most literature failed to quantitatively evaluate the level of green transformation of agriculture in China. Only Zhang [13] constructed an evaluation index system for green transformation of agricultural industry and analyzed the situation in Enshi, Hubei province, China, from three primary indicators including economy, society, and ecology and 26 secondary indicators. But, unfortunately, she did not measure the transformation. Li and Wang [14] used the DEMATEL (Decision Making Trial and Evaluation Laboratory) method to extract the influencing factors of agricultural green transformation from five dimensions covering factor supply, market demand, technological progress, institutional design, and subject capacity in Fujian province China. However, they used the questionnaire survey method to obtain data, which was relatively subjective, and the results might be questioned.

In terms of quantitative measurement of the agricultural green transformation level, the general practice in the current literature is to use agricultural green total factor productivity to measure indirectly. For example, Yan et al. [15] measured the green total factor productivity of agriculture in provinces of China based on the SBM (Slack Based Model) method and further investigated the influencing factors. In some other literature, the concept transformation 
is not directly used, but researchers also used the green total factor productivity to quantitatively measure the green agricultural development level in China, such as Li et al. [16], Yang and Chen [17], Wang et al. [18], Pan and Ying [19], Gao [20], Du et al. [21], Xiao and Chen [22], Zhang [23], Li et al. [24], and Ge et al. [25], who all used the input-output analysis method such as traditional DEA (Data Envelopment Analysis) or SBM models, considering the inputs covering pesticide, fertilizer, and agricultural films and total power of agricultural machinery in agricultural production, also desirable agricultural output and the undesirable output covering carbon emissions and agricultural pollution. They included constraints of resources and environment into the analysis framework. Some other literature further investigated the factors influencing the measured agricultural green total factor productivity, including environmental regulation, human capital, government input, farmers' income, foreign investment, research and development, and so on.

There is little focus on the relationship between the development of agricultural mechanization and agricultural green transformation. Currently scholars mainly discussed on topics such as how to measure the level of agricultural mechanization $[3,26,27]$, the influencing factors of agricultural mechanization development $[28,29]$, the spatial distribution of agricultural mechanization [30, 31], the influence of agricultural mechanization on agricultural production [32, 33], and so on. Ennouri and Kallel [34] stated that smart agricultural machines can enhance agricultural sustainability. $\mathrm{Wu}$ and Song [35] mentioned the impact of agricultural mechanization after measuring the agricultural green total factor productivity in the Chinese Yangtze River economic belt, and they found that the mechanization level showed a significant positive effect. Chen and Chen [36] set up simultaneous equations to represent relations among the agricultural mechanization, agricultural industrial upgrade, and agriculture carbon emissions, finding that agricultural mechanization has reduced agricultural carbon emissions. Yet, the abovementioned papers simply used agricultural machinery total power to represent the agricultural mechanization level, which may lead to a biased conclusion. Therefore, more comprehensive indices are needed to illustrate agricultural mechanization in order to better discuss the mutual relationship.

It can be concluded that, through reviewing the relevant literature, there is still potential for further research. First of all, the current quantitative measurement methods for agricultural green transformation such as SBM or traditional DEA models are mostly static, which are difficult to reflect the dynamics of transformation. Secondly, the existing discussion of the impact of agricultural mechanization on agricultural green transformation needs to be expanded in depth, which requires a more comprehensive measurement on the agricultural mechanization level. Finally, most of the studies focused on China as a whole, with less in-depth comparative analysis in a certain region. Therefore, the paper will, based on the dynamic connotation of agricultural green transformation, use the ML (Malmquist-Luenberger) index to quantitatively measure the level of agriculture green transformation in areas of China and, then, from the perspective of the comprehensive agricultural mechanization level, use a spatial econometric model to explore the impact of China's agricultural mechanization development on agriculture green transformation in western China, with the hope to contribute for existing research on agriculture green transformation, as well as the whole environment upgrading.

\section{Measurement of Agricultural Green Transformation in Western China}

3.1. The Agricultural Technology Modeling. Agriculture will produce all kinds of desirable agricultural products or good output people need, but it will also produce undesirable output or bad output including the nonpoint source pollution, water and soil destruction, and carbon dioxide emissions. In order to introduce the agricultural undesirable output into the measurement model of agricultural green transformation, this paper will use the nonparametric method to construct the environmental production frontier of China's agriculture.

The paper here firstly sets up a production possibility set, including both the good output and the bad output in the agricultural producing process, to represent the agricultural technology. It assumes that, in each region of China, the agricultural production employs input vector, with $x=\left(x_{1}, \ldots x_{N}\right) \in R_{+}^{N}$, and produces the good output vector $y$, with $y=\left(y_{1}, \ldots, y_{M}\right) \in R_{+}^{M}$, and also produces the bad output vector $b$, with $b=\left(b_{1}, \ldots, b_{I}\right) \in R_{+}^{I}$. Therefore, the agricultural production technology set can be defined by the following equation:

$$
P(x)=\left\{(y, b) ; x \cdot \text { can } \cdot \text { produce } \cdot(y, b), \quad x \in R_{+}^{N}\right\} .
$$

Output set $P(x)$ has three characteristics. They are closed, bounded, and convexity, respectively. Following Färe et al. [37], a DEA model can be formulated to construct the agricultural output sets that satisfy equation (1) as follows:

$$
P^{t}\left(x^{t}\right)=\left\{\left(y^{t}, b^{t}\right): \sum_{k=1}^{K} z_{k}^{t} y_{k m}^{t} \geq y_{m}^{t}, m=1, \ldots, M ; \sum_{k=1}^{K} z_{k}^{t} b_{k i}^{t}=b_{i}^{t}, i=1, \ldots, I ; \sum_{k=1}^{K} z_{k}^{t} x_{k n}^{t} \leq x_{n}^{t}, n=1, \ldots, N ; z_{k}^{t} \geq 0, k=1, \ldots, K\right\} .
$$


In equation (2), $z_{k}^{t}$ indicates the weight of each cross section observation value, and the nonnegative weight indicates that the production technology has the constant return to scale. $x_{k}^{t}$ represents those agricultural inputs in each year $t$ for the $k$ observation area, including agricultural demanded energy, labor, capital, water, land, fertilizer, pesticide, and films. $y_{k}^{t}$ represents those agricultural desirable output in each year $t$ for the $k$ observation area, namely, the gross agricultural output value. $b_{k}^{t}$ represents those agricultural undesirable output in each year $t$ for the $k$ observation area, including $\mathrm{CO}_{2}, \mathrm{TN}, \mathrm{TP}$, and pollution from pesticide and films. All the related input-output indicators are explained in Table 1.

As to the input indicators, Wu and Song [35] also included irrigation, diesel, and machines, which are not shown here, for the equipment needed for irrigation and agricultural machinery operation should be classified as agricultural fixed assets, which are already covered by capital input in this paper. Here, the capital is more comprehensive, also covering some other contents, such as agricultural production houses, water conservancy facilities, and pesticide application equipment and can better reflect the local government orientation on agriculture in China, which is because that free capital more likely prefers to go to other industries instead of agriculture, and the Chinese government always encourages the capital to enter into agriculture by issuing some tax incentive policies. Besides, the government also makes use of its fiscal expenditure to support the agricultural development. At the same time, pesticide, agricultural film, and fertilizer belong to the short-term inputs in agricultural production, which will not duplicate the capital index, so it can be kept. The input of diesel belongs to energy consumption. Although the main energy consumption in the agricultural production process is diesel, there are also other energy types such as coal, gasoline, and electricity consumed. Thus, it is more reasonable to use the energy aggregation index in this paper. The value of these input indicators would vary a lot in different places for that local government and farmers would adopt unequal measures to develop agriculture based on local geographical and economic conditions. For example, southwest China belongs to subtropical humid climate with abundant rainfall. Yet, northwest China belongs to extreme cold continental climate, which is dry and rainless. Therefore, the agriculture in the northwest would require more irrigation machinery and water input compared with the southwest.

In the bad output, the carbon dioxide $\left(\mathrm{CO}_{2}\right)$ discharged belonging to "real pollutants" does not contain nitrogen, phosphorus, and other nutrients, so carbon dioxide emission must be controlled $[25,38]$. This carbon dioxide emission volume needs to be estimated based on the agricultural energy data as the following equation shows:

$$
\mathrm{CO}_{2}=\sum_{i=1}^{2} \mathrm{CO}_{2, i}=\sum_{i=1}^{2} E_{i} \times \mathrm{NCV}_{i} \times \mathrm{CEF}_{i} \times \mathrm{COF}_{i} \times\left(\frac{44}{12}\right) .
$$

Equation (3) comes from the national greenhouse gas inventory guidelines from the Intergovernmental Panel on
Climate Change (IPCC), where the subscript $i$ is the number of agricultural energy types and $i=1,2$ represents two traditional energy sources that release carbon dioxide in agricultural production: coal and oil. $E$ represents the total agricultural energy consumption. NCV is the net calorific value of energy. CEF is the carbon emission coefficient, and $\mathrm{COF}$ is the carbon oxidation factor. For the specific estimation process, please refer to Guo and Huang [39].

In addition, most of the literature does not consider the pollution caused by use of pesticides and agricultural film. In this paper, the respective cultivated land load is adopted to approximately represent this kind of pollution, as Chen [40] did.

Other indicators are common in the agricultural nonpoint source pollution. According to the unit survey method from Lai et al. [41], Chen et al. [42], Liang [43], Yang and Chen [17], Xiao and Chen [22], and Zhang [23], this paper calculates the specific agricultural pollution emissions. First of all, it is essential to determine the pollution-generating units of agricultural pollution sources. Some literature believes that agricultural pollution is mainly caused by the loss of agricultural fertilizer, livestock and poultry breeding, agricultural solid waste such as crop straw, and rural domestic pollution emissions. These activities will indeed produce pollutants such as chemical oxygen demand (COD), total nitrogen (TN), and total phosphorus (TP). Among them, the fertilizer can be deemed as a pollutionproducing unit, for the necessity of its nitrogen and phosphorus pollution discharge. But, whether other agricultural activities can cause agricultural pollution is controversial [25]. Firstly, the manure from livestock and poultry breeding can form COD pollution easily if not properly treated, but it can also be positively used as organic fertilizer for planting industry. Especially in the recent years, the battle of agricultural nonpoint source pollution prevention and control has been launched. Also, scientists have made great progress in the harmless treatment technology of manure from livestock and poultry. After reasonable treatment, the manure can be transformed to biogas as a kind of useful energy. In addition, the biogas residue and biogas liquid can be used as a fertilizer with better effects than the chemical fertilizer. On the one hand, this can reduce the use of chemical fertilizer and save costs for farmers. On the other hand, it can also decrease the pollution caused by excessive application of chemical fertilizer and random stacking of livestock and poultry manure. Therefore, the manure from livestock and poultry breeding is not considered as a pollution production unit of agricultural nonpoint source pollution in this paper.

Secondly, it is difficult to reach a consensus on whether crop straws will cause pollution. On the one hand, researchers who agree that crop straw is an agricultural pollution production unit cannot unify opinions on its pollution production coefficient [40]. On the other hand, the premise of COD pollution from crop straws is to discard them directly. But, actually, there are not many crop straws discarded directly in agricultural production. Farmers can use them as a domestic fuel or can burn them in farmland or reuse them to obtain gas [44]. Therefore, crop straw is not deemed as agricultural solid waste in this paper. Finally, the 
TABle 1: The input-output index system.

\begin{tabular}{|c|c|c|}
\hline Classification & Names & Illustration \\
\hline \multirow{8}{*}{ Input } & Energy & $\begin{array}{c}\text { Sum of converted coal, oil, and electricity consumed in agricultural production (million tons of } \\
\text { standard coal) }\end{array}$ \\
\hline & Labor & Number of agricultural labor force (ten thousand people) \\
\hline & Capital & Fixed asset investment in agriculture ( 0.1 billion Yuan) \\
\hline & Water & Total water consumption for agricultural production ( 0.1 billion cubic meters) \\
\hline & Land & Cultivated land area (1000 hectares) \\
\hline & Fertilizer & $\begin{array}{l}\text { Total application amount of nitrogen, phosphorus, and compound fertilizer (calculated by the } \\
\text { conversion method) (ten thousand tons) }\end{array}$ \\
\hline & Pesticide & Pesticide usage (ton) \\
\hline & Film & Usage of agricultural plastic film (ton) \\
\hline Good output & Agricultural output & Gross output value of agriculture ( 0.1 billion Yuan) \\
\hline \multirow{5}{*}{ Bad output } & $\begin{array}{l}\text { Carbon dioxide } \\
\left(\mathrm{CO}_{2}\right)\end{array}$ & $\begin{array}{c}\text { The converted total amount of carbon dioxide emitted by energy sources such as coal and oil in } \\
\text { agricultural production (ten thousand tons) }\end{array}$ \\
\hline & Total nitrogen $(\mathrm{TN})$ & Nitrogen loss from nitrogen and compound fertilizers (ten thousand tons) \\
\hline & $\begin{array}{l}\text { Total phosphorus } \\
\text { (TP) }\end{array}$ & Phosphorus loss from phosphate fertilizer and compound fertilizer (ten thousand tons) \\
\hline & $\begin{array}{l}\text { Pollution from } \\
\text { pesticide }\end{array}$ & Farmland load of pesticides: pesticide use/cultivated land area (ton/1000 hectares) \\
\hline & Pollution from film & $\begin{array}{l}\text { Cultivated land load of agricultural film: usage of agricultural plastic film/cultivated land area (ton/ } \\
\qquad 1000 \text { hectares) }\end{array}$ \\
\hline
\end{tabular}

rural household waste is also not suitable as a source of agricultural pollution, for it should be classified as domestic pollution to be studied separately. Therefore, in this paper, the nonpoint source pollution caused by the loss of chemical fertilizer is selected as the pollution source, and the application amount of chemical fertilizer is taken as the pollution production unit. The specific pollutant discharge calculation formula is as follows:

$$
\mathrm{EM}=\sum_{i} \mathrm{EU}_{i} P_{i} C_{i}\left(\mathrm{EU}_{i}, S\right)
$$

In equation (4), EM represents the total emission of agricultural pollutants to be calculated. EU represents the pollution production units in the unit survey method. P is the pollution generating coefficient of each agricultural pollutant, and $\mathrm{C}$ is the loss coefficient of each agricultural pollutant. S represents some characteristics of the space where the agricultural pollutant is located, such as rainfall and water area. The pollution-generating unit has been determined above, where the total phosphorus (TP) quantity is to be multiplied by a coefficient of 0.4366 (determined by the chemical formula) by the pure amount of phosphorus fertilizer, while the pollutant-generating coefficient $\mathrm{P}$ and loss coefficient $\mathrm{C}$ are determined by reference to the data of Lai et al. [41], Liang [43], and Yang and Chen [17] and materials including the Agricultural Pollutant Discharge Coefficient Manual from the first national pollution source census.

\subsection{The Malmquist-Luenberger Measurement Based on Di-} rectional Distance Functions. The essence of incorporating environmental pollution into the calculation model of China's agricultural green transformation is to construct an environmental constraint by using a directional distance function. The purpose of the environmental constraint is to reduce pollution as much as possible and maintain sustainable development. According to the characteristics of agricultural production, the paper defines the following directional distance function based on the output, namely, equation (5), referring to Chung et al. [45], in order to reduce the unexpected output of agriculture while increasing the expected output.

$$
\vec{D}_{0}^{t}\left(x^{t}, y^{t}, b^{t} ; g\right)=\sup \left\{\beta:\left(y^{t}+\beta g_{y}, b^{t}-\beta g_{b}\right) \in p(x)\right\},
$$

where $g$ is the vector of the "direction" in which the output is scaled, $g=\left(g_{y},-g_{b}\right)$, representing the agricultural output. $\beta$ is the expansion proportion of desirable output and the contraction proportion of undesirable output under the given direction, input, and environment technology. If vector $g=(y,-b)$, it means that the desirable output is increased and the undesirable output is reduced in proportion under the given agricultural input. If vector $g=(y, 0)$, it means that the desirable output is increased in proportion and the undesirable output is unchanged under the given agricultural input. Meanwhile, if $\vec{D}_{0}^{t}\left(x^{t}, y^{t}\right.$, $\left.b^{t} ; g\right)=0$, it means that each area of China is effective on the agricultural production frontier. Also, $\vec{D}_{0}^{t}\left(x^{t}, y^{t}, b^{t} ; g\right)>0$ indicates that each area of China is not yet effective on the agricultural production frontier. With the further expansion of agricultural production, the impact on environmental pollution will also be intensified. Obviously, environmental pollution is a "bad" output, which should be restricted as much as possible in the process of agricultural production. So, here, it defines the directional vector $g=(y,-b)$.

The directional distance function can be used to construct the Malmquist-Luenberger (ML) index. In order to eliminate the randomness of period selection, the geometric means of two ML indexes are usually used to show the 
change of total factor productivity from the base period of $t$ period to the period of $t+1$. Following Chung et al. [45], the
ML index representing China's agricultural green transformation between time $t$ and $t+1$ can be defined as

$$
\begin{aligned}
\mathrm{ML}_{t}^{t+1} & =\left(\mathrm{ML}_{0}^{t} \times \mathrm{ML}_{0}^{t+1}\right)^{(1 / 2)} \\
& =\left\{\frac{1+\vec{D}_{0}^{t+1}\left(x^{t}, y^{t}, b^{t} ; g^{t}\right)}{1+\vec{D}_{0}^{t}\left(x^{t}, y^{t}, b^{t} ; g^{t}\right)} \times \frac{1+\vec{D}_{0}^{t+1}\left(x^{t+1}, y^{t+1}, b^{t+1} ; g^{t+1}\right)}{1+\vec{D}_{0}^{t}\left(x^{t+1}, y^{t+1}, b^{t+1} ; g^{t+1}\right)}\right\} \times\left\{\frac{1+\vec{D}_{0}^{t}\left(x^{t}, y^{t}, b^{t} ; g^{t}\right)}{1+\vec{D}_{0}^{t+1}\left(x^{t+1}, y^{t+1}, b^{t+1} ; g^{t+1}\right)}\right\} \\
& =\mathrm{MLTECH}_{t}^{t+1} \times \mathrm{MLEFFCH}_{t}^{t+1} .
\end{aligned}
$$

If the ML index is greater than 1 , it indicates that the agricultural green transformation level is growing from period $t$ to $t+1$. If the ML index is less than 1 , it indicates that the agricultural green transformation level is in a downward trend. If the ML index is equal to 1 , it indicates that the agricultural green transformation level stays unchanged.

At the same time, the ML index is divided into two parts: the technical progress rate $\mathrm{MLTECH}_{t}^{t+1}$ and output efficiency change $\mathrm{MLEFFCH}_{t}^{t+1}$. The technical progress rate $\mathrm{MLTECH}_{t}^{t+1}$ measures the movement of the frontier from $t$ to $t+1$, which is the change in the degree of green technical progress of agricultural production. When it is more than 1, it means that agricultural production technology has improved and contributed to the growth of green transformation. The output efficiency change $\mathrm{MLEFFCH}_{t}^{t+1}$ measures the change of the catching-up degree of the actual production and production frontier from $t$ to $t+1$. When it is more than 1, it means that the efficiency of agricultural production increases and contributes to the growth of green transformation.

There are four directional distance functions in equation (6), which can be calculated, respectively, as the solutions to linear programming (LP) problems. Two problems are solved in which all the observations are from the same period ( $t$ and $t+1$, respectively).

$$
\begin{aligned}
& \vec{D}_{0}^{t}\left(x^{t, k^{\prime}}, y^{t, k^{\prime}}, b^{t, k^{\prime}} ; y^{t, k^{\prime}},-b^{t, k^{\prime}}\right)=\operatorname{Max} \beta \\
& \text { s.t. } \sum_{k=1}^{K} z_{k}^{t} y_{k m}^{t} \geq(1+\beta) y_{k^{\prime} m}^{t}, \quad m=1, \ldots, M, \\
& \sum_{k=1}^{K} z_{k}^{t} b_{k i}^{t}=(1-\beta) b_{k^{\prime} i}^{t}, \quad i=1, \ldots I \\
& \sum_{k=1}^{K} z_{k^{t}}^{t} x_{k n}^{t} \leq x_{k^{\prime} n}^{t}, \quad n=1, \ldots, N \\
& z_{k}^{t} \geq 0, \quad k=1, \ldots, K .
\end{aligned}
$$

In equation (7), $z_{k}^{t}$ represents the weight of observation $k$, which is positive for the agricultural production technology and has constant returns to scale. Also, the result of $\vec{D}_{0}^{t+1}\left(x^{t+1, k^{\prime}}, y^{t+1, k^{\prime}}, b^{t+1, k^{\prime}} ; y^{t+1, k^{\prime}},-b^{t+1, k^{\prime}}\right)$ can be obtained by replacing $t$ with $t+1$ in equation (7).
The other two problems are mixed period ones. For example, the directional distance function for observation $k^{\prime}$ in period $t+1$, using period $t$ technology, can be calculated by solving the following LP problem:

$$
\begin{aligned}
& \vec{D}_{0}^{t+1}\left(x^{t, k^{\prime}}, y^{t, k^{\prime}}, b^{t, k^{\prime}} ; y^{t, k^{\prime}},-b^{t, k^{\prime}}\right)=\operatorname{Max} \beta \\
& \text { s.t. } \sum_{k=1}^{K} z_{k}^{t+1} y_{k m}^{t+1} \geq(1+\beta) y_{k^{\prime} m}^{t}, \quad m=1, \ldots, M, \\
& \sum_{k=1}^{K} z_{k}^{t+1} b_{k i}^{t+1}=(1-\beta) b_{k^{\prime} i}^{t}, \quad i=1, \ldots, I \\
& \sum_{k=1}^{K} z_{k}^{t+1} x_{k n}^{t+1} \leq x_{k^{\prime} n}^{t}, \quad n=1, \ldots N \\
& z_{k}^{t+1} \geq 0, \quad k=1, \ldots, K .
\end{aligned}
$$

$\vec{D}_{0}^{t}$ In $\left(x^{t+1, k^{\prime}}, y^{t+1, k^{\prime}}, b^{t+1, k^{\prime}} ; y^{t+1, k^{\prime}},-b^{t+1, k^{\prime}}\right)$ can be obtained by replacing $t$ with $t+1$ in equation (8).

\subsection{China's Agricultural Green Transformation Measurement} by the ML Index. This paper will use the abovementioned ML index to calculate western China's agricultural green transformation from the year 2008 to 2017 and divide the west into two subareas: the northwest and the southwest. Based on the abovementioned agricultural input-output indices in Table 1, adopting MaxDea software (http://www. maxdea.cn/), this paper uses the abovementioned directional distance function equation (5) and ML decomposition equation (6) to calculate agricultural green transformation in western China and the decomposition. The geometric average of each province's agricultural green transformation level in each year will be taken as the regional agricultural green transformation level in that year.

All data are collected from China Statistical Yearbook, China Rural Statistical Yearbook, China Agricultural Statistical Yearbook, China Environmental Statistical Yearbook, China Energy Statistical Yearbook, and Chinese provincial statistical yearbooks. In order to eliminate the impact of price fluctuations, data related to prices are converted into constant prices based on year 2008. It should be noted that the agriculture mentioned in this paper only 
refers to planting, that is, excluding another two industries in the first industry: forestry, animal husbandry, and fishery. Accordingly, when some planting industry's data cannot be collected, this paper uses the proportion of the planting industry output value in the total agricultural output as the weight to indirectly estimate. Table 2 shows the specific calculation results.

Table 2 shows that the average value of the agricultural green transformation level (from the ML index) in western China between 2008 and 2017 is 1.0324 . The results show that, in western China, although the agricultural green transformation is declining in some years, the overall agricultural green transformation has already achieved some accomplishments. The average annual change in the ML index is $3.24 \%$. This average is the combination of an efficiency advance of $5.62 \%$ and a technical decline of $2.56 \%$, indicating that the achieved accomplishments are mainly contributed by efficiency advance instead of technical progress. Specifically, the performance of southwest China is better than that of northwest China. The average value of southwest China in the past decade is 1.0412, with an average annual increase of $4.12 \%$, while the average value of northwest China is 1.0251, with an average annual increase of only $2.51 \%$. The main source of agricultural green transformation is the contribution of efficiency change in both the northwest and the southwest, and both regions are unsatisfactory in terms of technical improvement.

In order to investigate the agricultural green transformation in western China based on the national perspective, this paper will also calculate the level of 30 provinces in mainland China, including 11 provinces in the western region, 11 provinces in the eastern region (Beijing, Tianjin, Hebei, Liaoning, Shanghai, Jiangsu, Zhejiang, Fujian, Shandong, Guangdong, and Hainan), and 8 provinces in the central region (Shanxi, Jilin, Heilongjiang, Anhui, Jiangxi, Henan, Hubei, and Hunan). Figure 1 shows the changes in the agricultural green transformation of different areas over time.

It can be seen from Figure 1 that, in the past decade, the overall agricultural green transformation in the western region has shown a slight downward trend in fluctuation, basically consistent with the national trend, but slightly lower than the national average. All regions showed a significant decline in 2015 and 2016, which is closely related to the sluggish global economic growth and the decline of China's overall agricultural output growth rate in the past two years [46]. Fortunately, in 2017, the agricultural development of all regions turned back to the direction of green and sustainable development. Specifically, inside the western region, it can be found that the trend of the northwest and the southwest is basically consistent with the western region as a whole. The agricultural green transformation levels in most years of each region are positive. Although the number of provinces with agricultural green transformation level bigger than 1 is smaller than that of northwest China, the overall average value of southwest China is slightly higher than that of northwest China, mainly due to the high score of Chongqing in southwest China, which is about 1.3. Chongqing's agricultural green transformation level is in the first place in the whole western region, which is also higher than the national average. If the impact of Chongqing is removed, the level of agricultural green transformation in the four provinces of southwest China will be far lower than the average level of the six provinces of northwest China. However, the green transformation of agriculture in northwest China is also in the initial stage, weaker than that in the east. The agricultural green transformation in the whole western region, apart from Chongqing, is fluctuating at most times, showing strong dependence on investment covering fixed capital, labor, energy, and other production materials. So, for western China, the agricultural growth still shows an extensive mode, and it needs to strengthen the control of various pollution and emission problems in agricultural production. There is still a long way to go through for completely transforming the traditional production mode into a green and sustainable growth in the whole western region.

3.4. The Agricultural Green Transformation: Malmquist-Luenberger vs. Malmquist Approach. The original Malmquist index uses Shephard output distance functions to represent technology, defined as

$$
D_{0}(x, y, b)=\inf \left\{\theta: \frac{(y, b)}{\theta} \in P(x)\right\} .
$$

For each observation, the distance functions in the Malmquist index are computed as solutions of a linear programming problem. For example, for observation $k$,

$$
\begin{aligned}
& \left(D_{0}^{t}\left(x^{t, k^{\prime}}, y^{t, k^{\prime}}, b^{t, k^{\prime}}\right)\right)^{-1}=\max \theta \\
& \text { s.t. } \sum_{k=1}^{K} z_{k} y_{m k}^{t} \geq \theta y_{m k^{\prime}}^{t}, \quad m=1, \ldots, M, \\
& \sum_{k=1}^{K} z_{k} b_{i k}^{t}=\theta b_{i k^{\prime}}^{t}, \quad i=1, \ldots, I \\
& \sum_{k=1}^{K} z_{k} x_{n k}^{t} \leq \theta x_{n k^{\prime}}^{t}, \quad n=1, \ldots, N \\
& z_{k}^{t} \geq 0, \quad k=1, \ldots, K .
\end{aligned}
$$

The Shephard output distance functions constructing the original Malmquist index can express the wish to increase both the good output and bad output in proportion as much as possible, without considering decreasing the bad output, which is different from the directional distance functions. In order to test on the influence of a bad output on western China's agricultural green transformation, the paper will compare the results using the directional distance functions and the results using the traditional Malmquist productivity indices, which ignore the undesirable output.

Table 3 shows that, through ML index calculation, the average value of the overall agricultural green transformation level in western China is greater than 1, but still a little bit lower than the national average level. The national level is 
TABLE 2: Agricultural green transformation from 2008-2017 in west China.

\begin{tabular}{|c|c|c|c|c|c|c|c|c|c|}
\hline & \multicolumn{3}{|c|}{ West China in total } & \multicolumn{3}{|c|}{ Northwest China } & \multicolumn{3}{|c|}{ Southwest China } \\
\hline & ML & EFFCH & TECH & $\mathrm{ML}$ & EFFCH & TECH & ML & EFFCH & $\mathrm{TECH}$ \\
\hline $2007-2008$ & 1.093 & 1.095 & 0.994 & 1.077 & 1.073 & 1.003 & 1.112 & 1.121 & 0.983 \\
\hline 2008-2009 & 1.024 & 1.049 & 0.972 & 1.045 & 1.067 & 0.978 & 0.999 & 1.028 & 0.965 \\
\hline 2009-2010 & 0.930 & 0.9856 & 0.941 & 0.937 & 0.970 & 0.961 & 0.922 & 1.005 & 0.917 \\
\hline $2010-2011$ & 1.110 & 1.134 & 0.982 & 1.100 & 1.137 & 0.970 & 1.124 & 1.131 & 0.996 \\
\hline 2011-2012 & 1.123 & 1.096 & 1.016 & 1.028 & 1.0398 & 0.987 & 1.236 & 1.163 & 1.052 \\
\hline $2012-2013$ & 1.010 & 1.034 & 0.976 & 1.011 & 1.018 & 0.990 & 1.008 & 1.053 & 0.959 \\
\hline 2013-2014 & 1.079 & 1.106 & 0.975 & 1.069 & 1.078 & 0.988 & 1.090 & 1.140 & 0.960 \\
\hline $2014-2015$ & 0.924 & 0.970 & 0.947 & 0.928 & 0.966 & 0.957 & 0.919 & 0.975 & 0.935 \\
\hline $2015-2016$ & 0.964 & 0.993 & 0.968 & 1.014 & 1.016 & 0.998 & 0.904 & 0.966 & 0.932 \\
\hline $2016-2017$ & 1.067 & 1.098 & 0.973 & 1.042 & 1.079 & 0.967 & 1.097 & 1.121 & 0.979 \\
\hline Average & 1.032 & 1.056 & 0.974 & 1.025 & 1.045 & 0.980 & 1.041 & 1.070 & 0.968 \\
\hline
\end{tabular}

ML: Malmquist-Luenberger; MLEFFCH: Malmquist-Luenberger Efficiency Change; MLTECH: Malmquist-Luenberger Technical Change.

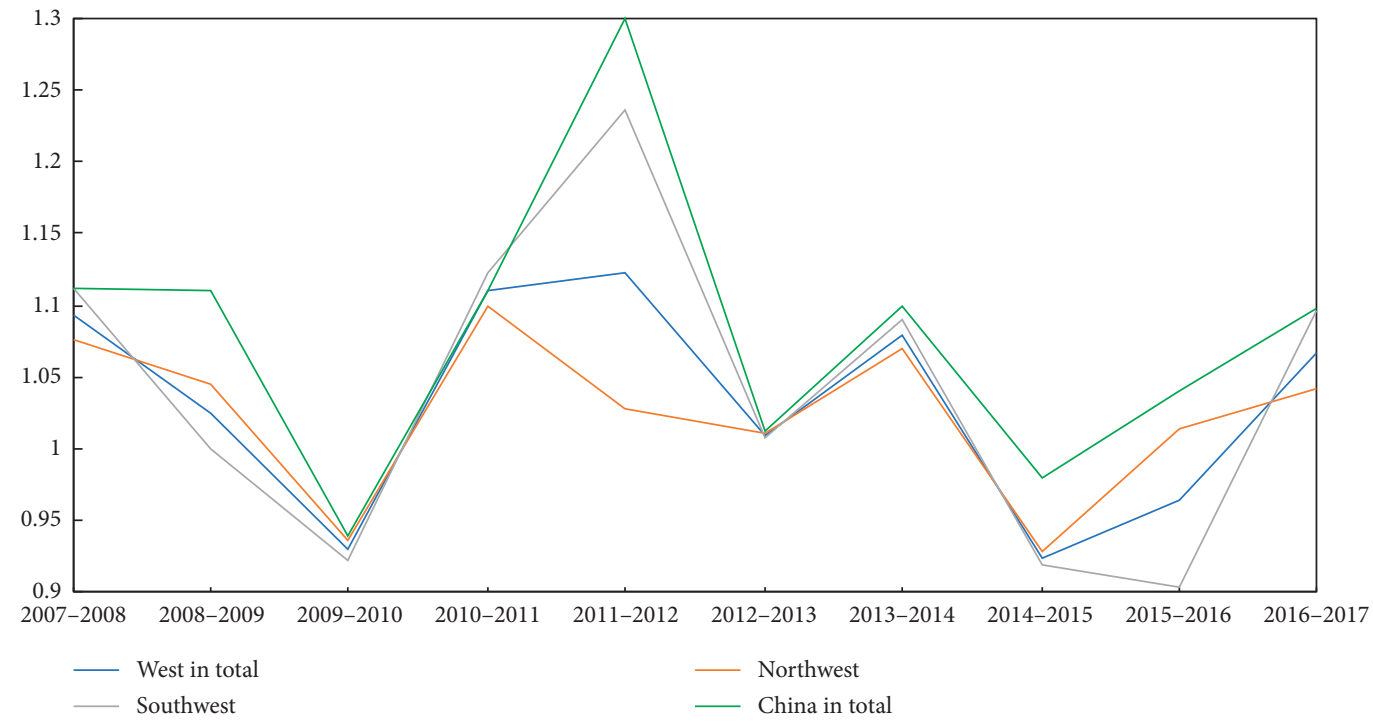

FIgURE 1: Trend of agricultural transformation in China.

mainly pulled up by the eastern region and is dragged down by the central region. Agriculture in the eastern region showed the most successful achievements in green transformation, with a green transformation level of 1.1350 . According to the success degree of agricultural green transformation, the whole China presents the "East-WestMiddle" rank pattern. As to specific provinces, it is found that the average ML index of six provinces (Gansu, Inner Mongolia, Ningxia, Xinjiang, Yunnan, and Chongqing) over the years is greater than 1, which indicates that their agricultural green transformation is more successful. Among them, Chongqing shows a very high level of green transformation, and the growth rate of green transformation is the quickest. In addition, five provinces (Guangxi, Guizhou, Qinghai, Shaanxi, and Sichuan) show negative growth of agricultural green transformation, indicating poor situation of green transformation. Among them, the performance of Guizhou is the worst in agricultural green transformation, requiring urgent action to put it right. In terms of bigger regions, the green transformation level in northwest China is relatively balanced, and the total agricultural output in this region also keeps a continuous growth trend. Therefore, most provinces in northwest China, such as Gansu, Xinjiang, Inner Mongolia, and Ningxia, have been on the way of agricultural green transformation. Although they are still not as good as the eastern China, they have great potential for future green development. By contrast, the five provinces in southwest China fluctuate greatly over the time, with Chongqing behaving the best and Guizhou behaving the poorest.

Table 3 also indicates that, for the whole west, when not considering the bad output, the decomposition results for the Malmquist index show that, over the year 2008 to 2017, the average technical change (MTECH) is $-1.71 \%$, and the average efficiency change (MEFFCH) has increased 6.09\%, indicating that the efficiency increase is the source of most of the total improvement $(4.55 \%)$. Technical progress was the greatest in the east $(2.43 \%$ per year), while other areas witnessed technical decline. It can also be seen that the transformation level without considering the bad output is 
TABLE 3: Agricultural green transformation level in China's regions.

\begin{tabular}{|c|c|c|c|c|c|c|c|}
\hline & \multirow{2}{*}{ Region } & \multicolumn{3}{|c|}{ With undesirable output } & \multicolumn{3}{|c|}{ Without undesirable output } \\
\hline & & ML & MLEFFCH & MLTECH & M & MEFFCH & MTECH \\
\hline \multirow{6}{*}{ Northwest } & Gansu & 1.0541 & 1.0688 & 0.9892 & 1.0841 & 1.0888 & 0.9976 \\
\hline & Inner Mongolia & 1.0093 & 1.0188 & 0.9888 & 1.0223 & 1.0218 & 0.9999 \\
\hline & Ningxia & 1.1086 & 1.1131 & 0.9943 & 1.1186 & 1.1141 & 1.0028 \\
\hline & Qinghai & 0.9634 & 0.9879 & 0.9717 & 0.9796 & 0.9909 & 0.9854 \\
\hline & Shaanxi & 0.9808 & 1.0261 & 0.9570 & 0.9911 & 1.0281 & 0.9643 \\
\hline & Xinjiang & 1.0343 & 1.0522 & 0.9788 & 1.0376 & 1.0640 & 0.9720 \\
\hline \multirow{9}{*}{ Southwest } & Guangxi & 0.9728 & 1.0008 & 0.9723 & 0.9835 & 1.0018 & 0.9823 \\
\hline & Guizhou & 0.9201 & 1.0232 & 0.8978 & 0.9371 & 1.0202 & 0.9179 \\
\hline & Sichuan & 0.9489 & 1.0024 & 0.9470 & 0.9522 & 0.9841 & 0.9655 \\
\hline & Yunnan & 1.0523 & 1.0452 & 1.0000 & 1.0583 & 1.0702 & 0.9878 \\
\hline & Chongqing & 1.3118 & 1.2793 & 1.0221 & 1.3358 & 1.2863 & 1.0366 \\
\hline & The west & 1.0324 & 1.0562 & 0.9744 & 1.0455 & 1.0609 & 0.9829 \\
\hline & The east & 1.1350 & 1.1082 & 1.0239 & 1.2831 & 1.2532 & 1.0234 \\
\hline & The middle & 0.9717 & 0.9836 & 0.9891 & 0.9858 & 0.9937 & 0.9916 \\
\hline & All regions & 1.0802 & 1.0691 & 1.0112 & 1.1039 & 1.0735 & 1.0294 \\
\hline
\end{tabular}

ML: Malmquist-Luenberger; MLEFFCH: Malmquist-Luenberger Efficiency Change; MLTECH: Malmquist-Luenberger Technical Change; M: Malmquist; MEFFCH: Malmquist Efficiency Change; MTECH: Malmquist Technical Change.

$1.31 \%$ overestimated, in which the efficiency improvement is $0.47 \%$ overestimated, and the technological progress is 0.85 overestimated. Obviously, whether to introduce bad output into the agricultural green transformation has a significant impact on the real value of the green transformation level. This overestimation is not only reflected in the western region but also has the same effect in the whole country and other regions. Especially in eastern China, the overestimation is the highest, reaching $14.81 \%$.

\section{Influence of Agricultural Mechanization on Green Transformation in Western China}

4.1. The Definition of Agricultural Mechanization. Some literature directly uses the total power of agricultural machinery as the measurement of the agricultural mechanization level [47, 48]. But, the index of machinery total power is difficult to represent the real development degree of agricultural mechanization in a certain region, for the existence of cross regional operation of agricultural machines and the difference of the actual operation efficiency. Therefore, some other scholars have established an index system to measure the level of agricultural mechanization $[3,49,50]$, including the size level, operation level, profit level, and economic level, but such complex index system has covered too many factors not closely related to agricultural machinery, which is easy to duplicate with the calculation of dependent variables.

Therefore, this paper finds a middle ground to examine the degree of agricultural mechanization from two basic perspectives. On the one hand, the total power of agricultural machinery is used to represent the equipment level of agricultural mechanization, represented by MechE. On the other hand, since the agricultural machinery can be used in five production activities, namely, land cultivation, crop sowing, farmland irrigation, crop protection, and crop harvesting, the operation level of agricultural mechanization can be represented as MechO, obtained by using the geometric mean of five ratios, that is, the mechanized landcultivation rate, mechanized crop-sowing rate, mechanized farmland-irrigation rate, mechanized crop-protection rate, and mechanized crop-harvesting rate. Among them, the mechanized land-cultivation rate is equal to the mechanized cultivation area divided by the total cultivation area, the mechanized crop-sowing rate is equal to the mechanized sowing area divided by the total sowing area, and the mechanized farmland-irrigation rate is equal to the mechanized irrigation area divided by the total irrigation area. The mechanized crop-protection rate is equal to the area of mechanized crop-protection divided by the total area of crop-protection. The mechanized crop-harvesting rate is equal to the area of mechanized harvesting divided by the total harvest area. All data given above are mainly derived from the China Statistical Yearbook and China Agricultural Machinery Industry Yearbook. The operation level and equipment level of agricultural mechanization in western China are shown in Tables 4 and 5.

Comparing Tables 4 and 5, it can be found that the agricultural mechanization operation level in the northwest is better than that in the southwest, while the agricultural mechanization equipment level (that is, the total power of agricultural machinery) in the northwest is significantly lower than that in the southwest. This is due to the fact that the southwest China enjoys a higher agricultural output than the northwest China, leading to bigger consumption on agricultural machines. However, the farming land in the southwest is more fragmented by hills and mountains, resulting in a lower mechanization operation level. In general, the mechanized operation level in the whole western region is not very satisfying, but fortunately, the operation level and the equipment level have maintained a good trend of yearly increase.

4.2. Spatial Characteristics of Agricultural Green Transformation. First of all, it is necessary to judge whether 
TABLE 4: Agricultural mechanization operation level.

\begin{tabular}{lcccccccccc}
\hline & 2008 & 2009 & 2010 & 2011 & 2012 & 2013 & 2014 & 2015 & 2016 & 2017 \\
\hline Inner Mongolia & 0.43 & 0.45 & 0.49 & 0.54 & 0.55 & 0.58 & 0.59 & 0.62 & 0.63 & 0.59 \\
Shaanxi & 0.33 & 0.36 & 0.38 & 0.40 & 0.41 & 0.41 & 0.42 & 0.44 & 0.44 & 0.44 \\
Gansu & 0.29 & 0.27 & 0.27 & 0.27 & 0.26 & 0.27 & 0.29 & 0.30 & 0.31 & 0.32 \\
Qinghai & 0.28 & 0.30 & 0.30 & 0.31 & 0.31 & 0.30 & 0.34 & 0.35 & 0.39 & 0.38 \\
Ningxia & 0.24 & 0.28 & 0.32 & 0.34 & 0.36 & 0.38 & 0.39 & 0.39 & 0.40 & 0.40 \\
Xinjiang & 0.39 & 0.49 & 0.47 & 0.48 & 0.50 & 0.51 & 0.52 & 0.61 & 0.61 & 0.60 \\
Guangxi & 0.07 & 0.12 & 0.13 & 0.17 & 0.20 & 0.21 & 0.24 & 0.27 & 0.28 & 0.30 \\
Chongqing & 0.10 & 0.11 & 0.14 & 0.16 & 0.17 & 0.18 & 0.19 & 0.19 & 0.20 & 0.21 \\
Sichuan & 0.13 & 0.14 & 0.14 & 0.15 & 0.17 & 0.19 & 0.23 & 0.25 & 0.26 & 0.27 \\
Guizhou & 0.05 & 0.04 & 0.04 & 0.06 & 0.07 & 0.08 & 0.08 & 0.09 & 0.10 & 0.12 \\
Yunnan & 0.04 & 0.06 & 0.08 & 0.12 & 0.13 & 0.15 & 0.15 & 0.16 & 0.17 & 0.18 \\
\hline
\end{tabular}

TABLE 5: Agricultural mechanization equipment level (10 thousand kilowatt).

\begin{tabular}{lcccccccccc}
\hline & 2008 & 2009 & 2010 & 2011 & 2012 & 2013 & 2014 & 2015 & 2016 & 2017 \\
\hline Inner Mongolia & 2209 & 2779 & 2892 & 3034 & 3173 & 3281 & 3431 & 3633 & 3805 & 3331 \\
Shaanxi & 1576 & 1710 & 1833 & 2000 & 2183 & 2350 & 2453 & 2552 & 2667 & 2172 \\
Gansu & 1577 & 1686 & 1823 & 1978 & 2136 & 2279 & 2418 & 2546 & 2685 & 1904 \\
Qinghai & 349 & 356 & 389 & 421 & 431 & 435 & 411 & 441 & 454 & 459 \\
Ningxia & 630 & 658 & 703 & 729 & 769 & 787 & 802 & 813 & 831 & 581 \\
Xinjiang & 1275 & 1376 & 1503 & 1644 & 1797 & 1969 & 2166 & 2342 & 2489 & 2552 \\
Guangxi & 2127 & 2374 & 2551 & 2768 & 3033 & 3196 & 3383 & 3567 & 3803 & 3527 \\
Chongqing & 860 & 903 & 967 & 1071 & 1140 & 1162 & 1199 & 1243 & 1300 & 1319 \\
Sichuan & 2523 & 2688 & 2953 & 3155 & 3426 & 3694 & 3953 & 4160 & 4405 & 4267 \\
Guizhou & 1412 & 1538 & 1606 & 1730 & 1851 & 2107 & 2241 & 2458 & 2575 & 2041 \\
Yunnan & 1862 & 2014 & 2159 & 2411 & 2628 & 2874 & 3070 & 3215 & 3333 & 3441 \\
\hline
\end{tabular}

there is a spatial dependence or spatial correlation among the main bodies (that is, different China's regions) of agricultural green transformation. In this paper, Moran's I index is used to determine whether this spatial correlation exists. Moran's I was first proposed in 1950 by Pierce Moran, an Australian statistician.

$$
\text { Moran's } I=\frac{\sum_{i=1}^{n} \sum_{j=1}^{n} W_{i j}\left(x_{i}-\bar{x}\right)\left(x_{j}-\bar{x}\right)}{\sum_{i=1}^{n} \sum_{j=1}^{n} W_{i j} \cdot \sum_{i=1}^{n}\left(x_{i}-\bar{x}\right)^{2} / n}, \quad \text { Moran'sI } \in[-1,+1]
$$

where $W_{i j}$ represents any element in a binary space $(i, j)$ weight matrix and $n$ represents the number of regions, which is 11 in this study. $x_{i}, x_{j}$ are the agricultural green transformation of province $i$ and province $j$, respectively. If Moran's $I$ equals to 0 , it means that there is no spatial correlation among provinces as respect to the agricultural green transformation in western China during the investigation period. If Moran's I is bigger than 0, it means that there is a significant positive spatial agglomeration among provinces as respect to the agricultural green transformation. If Moran's I value is smaller than 0 , it means that there is a significant negative spatial correlation or spatial diffusion in western China.

From Table 6 which is obtained from the Matlab software (https://www.mathworks.com/products/matlab.html), it can be seen that the agricultural green transformation of the 11 provinces in western China has significant spatial correlation, and this spatial correlation gradually increases from year 2008 to 2017, which indicates that the ordinary panel model is no longer applicable due to the data's nonindependence, violating the classical hypothesis of the ordinary panel model, proving that using the spatial econometric model will be more reasonable than an ordinary panel model.

4.3. Spatial Econometric Model Setting. After confirming that there is a significant spatial correlation among provinces as respect to agricultural green transformation, the spatial econometric model can be built. In view of the obvious spatial correlation characteristics of the agricultural green transformation level in western China, this paper will build a spatial panel model based on the abovementioned principles to explore the impact of agricultural mechanization on the green transformation. The spatial panel model is established based on the New Growth Theory. The following production function will be used:

$$
Y=A,(\operatorname{Mech} O, \operatorname{Mech} E, Z, t) \times F(K, L),
$$

where $Y$ stands for the agricultural output. $A(\cdot)$ stands for the agricultural green transformation level of 11 provinces in western China considering an undesirable output. $Z$ stands for other factors (namely, control variables). $K$ stands for capital input, and $L$ stands for the labor input. Referring to Hulten et al. [51], it is assumed that $A(\cdot)$ satisfies Hicks neutral, and its components are multiple combinations. 
TABLE 6: Moran's I value of the agricultural green transformation level in western China.

\begin{tabular}{|c|c|c|c|c|c|c|c|c|c|c|}
\hline & 2008 & 2009 & 2010 & 2011 & 2012 & 2013 & 2014 & 2015 & 2016 & 2017 \\
\hline M & 0.032 & 0.154 & 0.121 & 0.109 & 0.331 & 0.290 & 0.301 & 0.386 & 0.369 & 0.416 \\
\hline Value & $*$ & $* *$ & $*$ & $*$ & $* *$ & $* *$ & $*$ & $* *$ & $* *$ & $* * *$ \\
\hline
\end{tabular}

Notes: ${ }^{* * *},{ }^{* *}$, and ${ }^{*}$ represent the significance levels of $1 \%, 5 \%$, and $10 \%$, respectively.

$$
A(\operatorname{Mech} O, \operatorname{Mech} E, Z, t)=A_{i 0} \operatorname{MechO}_{i t}^{\varepsilon i} \operatorname{Mech} E_{i t}^{\phi i} Z_{i t}^{\theta i},
$$

where $A_{i 0}$ is the initial level of agricultural green transformation in 11 provinces in western China. $\varepsilon, \phi$, and $\theta$ are influencing parameters of factors such as $\mathrm{Mech} O$, MechE, and others on the agricultural green transformation efficiency. Then, bringing equation (13) into equation (12), the following equation can be obtained:

$$
Y_{i t}=A_{i 0} \operatorname{MechO}_{i t}^{\varepsilon i} \operatorname{Mech} E_{i t}^{\phi i} Z_{i t}^{\theta i} \times F\left(K_{i t}, L_{i t}\right) .
$$

According to the previous ML index calculation theorem, both sides of equation (14) can be divided by $F\left(K_{i t}, L_{i t}\right)$ at the same time to get

$$
T_{i t}=\frac{Y_{i t}}{F\left(K_{i t}, L_{i t}\right)}=A_{i 0} \operatorname{MechO}_{i t}^{\varepsilon i} \operatorname{Mech}_{i t}^{\phi i} Z_{i t}^{\theta i} .
$$

The logarithm of both sides of the abovementioned equation can be obtained as follows:

$$
\ln T_{i t}=\ln A_{i 0}+\varepsilon_{i} \ln \mathrm{MechO}_{i t}+\phi_{i} \ln \mathrm{Mech}_{i t}+\theta_{i} \ln Z_{i t} .
$$

Then, based on equation (16), according to Anselin et al. [52], the paper introduces the spatial lag term, the spatial error term, and the spatial weight matrix. The following spatial econometric model can be obtained after simplification:

$$
T_{i t}=A_{i 0}+\varepsilon_{i} \mathrm{MechO}_{i t}+\phi_{i} \mathrm{Mech}_{i t}+\theta_{i} Z_{i t}+\rho W T_{i t}+\xi_{i t} .
$$

$$
\begin{aligned}
T_{i t} & =A_{i 0}+\varepsilon_{i} \operatorname{MechO}_{i t}+\phi_{i} \operatorname{Mech} E_{i t}+\theta_{i} Z_{i t}+\xi_{i t}, \\
\xi_{i t} & =\lambda W \xi_{i t}+\mu_{i t} .
\end{aligned}
$$

The spatial lag model (SLM) is in the form of equation (17), and the spatial error model (SEM) is in the form of equation (18). In the equations, $\rho$ and $\lambda$ represent the spatial lag term and the spatial error term of the models, respectively. The subscript $i$ represents each western province. $W$ is the spatial weight matrix established in this paper, which uses the first-order adjacent function matrix, that is, the adjacent provinces are recorded as 1 , and the nonadjacent provinces are recorded as 0 . Also, $\varepsilon$ and $\mu$ are random error terms. Besides, $Z$ is the control variable, meaning other factors that affect agricultural green transformation. This paper chooses the following controlling factors. The farmers' income (inc) refers to the percapita disposable income of farmers in the region, and the local government expenditure (gov) is approximately represented by the local government's expenditure on agricultural, forestry, and water facilities. The regional human capital (edu) uses the rural population in the region with an education background of high school and above. The regional agricultural technology (tec) is characterized by the number of agricultural technical personnel in public-owned enterprises and institutions in each region. The data involved in these variables are mainly from the China Statistical Yearbook, provincial statistical yearbooks, China Science and Technology Statistical Yearbook, China Population and Employment Statistical Yearbook, and other government documents such as provincial annual reports. In order to eliminate the influence of price, all the abovementioned indexes related to price are converted into constant price based on the year 2008 .

There are some methods to determine whether SLM or SEM is more appropriate: the likelihood ratio test, Wald test, Lagrange multiplier (LM) test, and AIC test. Here, the LM criterion is proposed.

$$
\begin{gathered}
\text { LMERR }=\frac{\left[\left(e^{\prime} W e\right) /\left(e^{\prime} e / N\right)\right]^{2}}{\left[\operatorname{tr}\left(W^{2}+W^{\prime} W\right)\right]} . \\
\text { LMLAG }=\left[\frac{\left(e^{\prime} W y\right) /\left(e^{\prime} e / N\right)}{D}\right]^{2},
\end{gathered}
$$

where tr represents the trace operator of the matrix, $e$ is the OLS regression residual vector, $W$ is the spatial weight matrix, and $N$ is the number of provinces, which is 11 here. $D=\left[(W X \beta)^{\prime} M(W X \beta) / \sigma^{2}\right]+\operatorname{tr}\left(W^{2}+W^{\prime} W\right), W X \beta$ is the spatial lag of the predicted value $X \beta$, and $M=I-X(X, X)^{-1} X \prime$. The LMERR (Lagrange multiplier (error)) test and LMLAG (Lagrange multiplier (lag)) test both obey the distribution $\chi^{2}(1)$. When the LMLAG value is greater than LMERR and R-LMLAG (Robust LM (lag)) is more significant than R-LMERR (Robust LM (error)), it indicates that the correct source of spatial correlation is more likely to be a missing spatial lag variable, so the spatial lag model can be selected. Otherwise, the spatial error model is selected. The results of the Lagrange multiplier test are shown in Table 7.

From Table 7, it can be found that the statistical values of LMERR and R-LMERR are significantly higher than those of LMLAG and R-LMLAG for the whole western China and the northwestern region, which shows that the SEM model is more reasonable than the SLM model in these two places. For the southwestern region, the result is just the opposite, indicating that the SLM model should be used here. Then, the Hausman test is adopted to determine whether the fixed effect model is better than the random effect model. Finally, it is necessary to decide whether the fixed effect model is time-fixed, space-fixed, or time and space two-way-fixed. After repeated regressions, this paper decides to choose the time and space two-way-fixed model. 
TABLE 7: Lagrange multiplier test result.

\begin{tabular}{|c|c|c|c|}
\hline & Test & Value & Probability \\
\hline \multirow{4}{*}{$\begin{array}{l}\text { West China in } \\
\text { total }\end{array}$} & $\begin{array}{l}\text { Lagrange multiplier } \\
\text { (lag) }\end{array}$ & 1.3837 & 0.5712 \\
\hline & Robust LM (lag) & 62.3743 & 0.0001 \\
\hline & $\begin{array}{l}\text { Lagrange multiplier } \\
\text { (error) }\end{array}$ & 7.3995 & 0.0694 \\
\hline & Robust LM (error) & 68.3901 & 0.0000 \\
\hline \multirow{4}{*}{ Northwest China } & $\begin{array}{l}\text { Lagrange multiplier } \\
\text { (lag) }\end{array}$ & 2.3424 & 0.5735 \\
\hline & Robust LM (lag) & 45.8379 & 0.0002 \\
\hline & $\begin{array}{l}\text { Lagrange multiplier } \\
\text { (error) }\end{array}$ & 6.5919 & 0.0564 \\
\hline & Robust LM (error) & 50.0874 & 0.0006 \\
\hline \multirow{4}{*}{ Southwest China } & $\begin{array}{l}\text { Lagrange multiplier } \\
\text { (lag) }\end{array}$ & 4.6757 & 0.0781 \\
\hline & Robust LM (lag) & 65.4127 & 0.0004 \\
\hline & $\begin{array}{l}\text { Lagrange multiplier } \\
\text { (error) }\end{array}$ & 2.1890 & 0.1765 \\
\hline & Robust LM (error) & 62.9260 & 0.0008 \\
\hline
\end{tabular}

4.4. Empirical Results Analysis. After setting up the model, the paper continues to use the MATLAB software to conduct the spatial empirical analysis for western China and divide the whole west into two segments: northwest and southwest, respectively. In order to make a comparison, this paper also carries out the traditional panel estimation with time and space two-way-fixed. The specific results are shown in Table 8.

Table 8 shows that the spatial error terms in the whole west and northwest and the spatial lag term in southwest China are all significant. The goodness of fit $\left(R^{2}\right)$ and the logarithm likelihood value for the three spatial models are all better than that of the traditional model. It proves that agricultural green transformation in west China can not only be affected by the local agricultural mechanization, but also strongly affected by the surrounding area's spatial spillover. Meanwhile, coefficients of both the traditional model and the spatial model are quite consistent, indicating the robustness of the model regression.

As can be seen from the regression results in Table 8, the influence of the two indicators of agricultural mechanization on the agricultural green transformation in the west presents opposite characteristics, both in the traditional panel model and the spatial panel model. The agricultural mechanization operation level (MechO) shows the positive impact to the green transformation of agriculture, while the agricultural mechanization equipment level (MechE) shows the opposite force, which is consistent in the northwest, southwest, and the whole western region. Compared with southwest China, the agricultural mechanization in northwest China has more positive influence on its balanced green transformation. Therefore, for the green and sustainable development of agriculture, China should pay more attention to the operation efficiency of agricultural machinery, rather than simply the total power of agricultural machinery. This is also the reason why the 13th Five-year Plan for Agricultural Mechanization Development China has canceled the quantitative indicator of "total power of agricultural machinery". Agricultural machinery total power is only a general equipment level, failing to reflect the actual agricultural machine types and quality $[49,50]$. In many western provinces, especially in the western mountainous regions, farmers have very low income and can only afford to buy those environmental friendly machines for one time and are reluctant to give up the old and long-time used machines. So, many agricultural machines in these places have been used for too long time, with very high energy consumption and high emission, leading to more energy consumption and emission, forming obstacles to agricultural green transformation. At present, the agricultural machinery power per $\mathrm{mu}$ in China is higher than that of many agriculturallydeveloped countries, but China's agricultural green transformation level still lags behind, which once again proves that the simple index of agricultural machinery total power cannot ensure the agricultural sustainable development. In contrast, the mechanization operation level can more vividly reflect the degree of machinery usage in agricultural production. If the agricultural machines are used in a more reasonable and efficient way, the application of agricultural materials will be more efficient, leading to less harm on the environment. For example, the new ultra-low-altitude remote-controlled drone, connected with a large transplanter, can transplant rice seedlings at high speed and accurately control the spray volume of pesticides and fertilizers at the same time, with a very accurate spraying location. This agricultural operation technology can improve the efficiency of farming and plant protection, while decreasing the use of fertilizers and pesticides and limiting the negative impact on the environment. However, since the mountainous and hilly areas in southwest China are bigger than those in northwest China, the operation level of agricultural mechanization in southwest China is relatively lower, and this positive impact on agricultural green transformation shows weaker influence than that in northwest China.

As to the results of control variables' regression, the coefficient of farmers' income (inc) index is significantly positive in the west, but it does not pass the test of significance in northwest China and shows the negative influence on agricultural green transformation. This difference in northwest China is possibly due to the fact that farmers in northwest earn a little bit less than those in the southwest, and also, the land in the northwest is relatively poor, with worse climate and scarce water. Therefore, a farmer's low income in northwest China has not effectively affected the agricultural green transformation. It reminds the government that China can only improve a farmer's income by developing the rural economy. When farmers do not have to worry about basic living needs, they can have the motivation to pay attention to environmental protection. The local government fiscal expenditure (gov) index did not pass the significance test at most times, possibly due to the reason that the paper did not breakdown the government spending, which covers only a small part of money on the agricultural science and technology input, and most governments spend a lot on the rural government sector, rural infrastructure construction, and rural relief, so in the west China, the whole government spending did not play a significant role in 
TABLE 8: The result of the spatial panel model.

\begin{tabular}{|c|c|c|c|c|c|c|}
\hline & \multicolumn{2}{|c|}{ West China in total } & \multicolumn{2}{|c|}{ Northwest China } & \multicolumn{2}{|c|}{ Southwest China } \\
\hline & Traditional model & SEM model & Traditional model & SEM model & Traditional model & SLM model \\
\hline MechO & $1.5829^{* * *}$ & $2.4764^{* * *}$ & $1.9363^{* *}$ & $3.1809^{* *}$ & $1.1812^{*}$ & $1.2562^{*}$ \\
\hline MechE & $-1.3791^{*}$ & $-2.6848^{* * *}$ & $-5.0178^{* *}$ & $-5.5917^{* *}$ & $-3.2933^{*}$ & $-2.8847^{* * *}$ \\
\hline inc & $0.3817^{*}$ & $0.4512^{* *}$ & -3.9921 & -3.4939 & $1.0089^{* *}$ & $1.7608^{* * *}$ \\
\hline gov & -0.1032 & $-0.1049^{*}$ & -0.5339 & -0.4908 & -0.9790 & $-0.9183^{*}$ \\
\hline edu & $18.2741^{* * *}$ & $24.0803^{* * *}$ & $25.4634^{* * *}$ & $27.3269^{* * *}$ & $-3.5488^{* *}$ & $-2.4809^{* *}$ \\
\hline tec & $0.9936^{* *}$ & $1.0949^{* * *}$ & $2.1857^{*}$ & $4.9278^{* *}$ & $0.4372^{*}$ & $1.0484^{* *}$ \\
\hline Spatial error & - & $0.6060^{* * *}$ & - & $0.8030^{* * *}$ & - & - \\
\hline Spatial lag & - & - & - & - & - & $0.5450^{* * *}$ \\
\hline$R^{2}$ & 0.5039 & 0.6833 & 0.4637 & 0.5332 & 0.4075 & 0.4591 \\
\hline Log likelihood & -40.1692 & -36.5326 & -52.5318 & -49.3824 & -61.3782 & -58.9581 \\
\hline
\end{tabular}

Notes: ${ }^{* * *},{ }^{* *}$, and ${ }^{*}$ represent the significance levels of $1 \%, 5 \%$, and $10 \%$, respectively.

TABLE 9: Moran's I value under the economic spatial weight matrix.

\begin{tabular}{lcccccccccc}
\hline & 2008 & 2009 & 2010 & 2011 & 2012 & 2013 & 2014 & 2015 & 2016 & 2017 \\
\hline $\mathrm{M}$ & 0.028 & 0.059 & 0.102 & 0.124 & 0.302 & 0.297 & 0.334 & 0.397 & 0.399 \\
$* *$ & $* *$ & 0.422 \\
Value & $*$ & $* *$ & $*$ & $*$ & $* *$ & $* *$ \\
\hline
\end{tabular}

Notes: ${ }^{* * *},{ }^{* *}$, and ${ }^{*}$ represent the significance levels of $1 \%, 5 \%$, and $10 \%$, respectively.

TABLE 10: LM test under the economic spatial weight matrix.

\begin{tabular}{|c|c|c|c|}
\hline & Test & Value & Probability \\
\hline \multirow{4}{*}{$\begin{array}{l}\text { West China in } \\
\text { total }\end{array}$} & $\begin{array}{l}\text { Lagrange multiplier } \\
\text { (lag) }\end{array}$ & 2.3951 & 0.4509 \\
\hline & Robust LM (lag) & 66.4917 & 0.0001 \\
\hline & $\begin{array}{l}\text { Lagrange multiplier } \\
\text { (error) }\end{array}$ & 9.5626 & 0.0572 \\
\hline & Robust LM (error) & 73.6592 & 0.0000 \\
\hline \multirow{4}{*}{ Northwest China } & $\begin{array}{l}\text { Lagrange multiplier } \\
\text { (lag) }\end{array}$ & 1.3986 & 0.6582 \\
\hline & Robust LM (lag) & 51.5939 & 0.0001 \\
\hline & $\begin{array}{l}\text { Lagrange multiplier } \\
\text { (error) }\end{array}$ & 9.9785 & 0.0471 \\
\hline & Robust LM (error) & 60.1738 & 0.0005 \\
\hline \multirow{4}{*}{ Southwest China } & $\begin{array}{l}\text { Lagrange multiplier } \\
\text { (lag) }\end{array}$ & 4.1362 & 0.0709 \\
\hline & Robust LM (lag) & 55.1936 & 0.0004 \\
\hline & $\begin{array}{l}\text { Lagrange multiplier } \\
\text { (error) }\end{array}$ & 4.0918 & 0.0825 \\
\hline & Robust LM (error) & 55.1492 & 0.0006 \\
\hline
\end{tabular}

promoting the green transformation for agriculture [22]. The influence of the regional human capital (edu) is significant, but there is differentiation between the southwestern and northwestern regions. In the northwest and the whole west, the farmers' education improvement has a significant positive impact on the local agricultural green transformation, which is consistent with many researchers. However, this is not always true in the southwestern region [23]. There was only about $10 \%$ of southwestern rural population with a senior high school or above education background in the year 2017, while this number climbed to $15 \%$ in the northwest China. This gap in education possibly leads to the difference in concepts on longer plans. Therefore, in most places of west China, especially the northwest, farmers with higher education background would pay more attention on future sustainable development of agriculture. But, in some backward southwestern places, many farmers fail to receive high school education or above, and thus, their education cannot function as the thrust for the local agricultural green transformation. The agricultural technical (tec) index in all areas showed a positive significant influence, which indicates that if there are more agricultural technicians functioning in the process of agricultural production, it will be more effective for the farmers to make use of agricultural materials. Also, the farmers will be also more likely to realize the importance of environmental protection and pollution control in the agricultural sustainable development.

4.5. Robustness Tests. To enhance the robustness of the results, an alternative spatial weight matrix is utilized here, given the fact that the level of regional economic development is spatially correlated, which is an economic spatial weight matrix, represented by the product of the reciprocal of the shortest feasible distance between province $i$ and province $j$ and the ratio of province $i$ 's annual mean of percapita GDP to all provinces' annual mean of per capita GDP.

Moran's I values of the agricultural green transformation of the 11 provinces in western China under the economic spatial weight matrix are significant (as shown in Table 9), which is similar to the previous results.

As seen from Table 10, under the new matrices, in the whole western China and the northwestern region, the values of LMERR and R-LMERR statistics are higher than those of LMLAG and R-LMLAG, which is similar to the previous results, indicating that these two regions are suitable for the SEM model. The difference is in the southwestern region of China, where the Robust LM tests could not help identify the better model. In this case, the $R^{2}$ and log-likelihood values are adopted to conduct further 
TABLE 11: Results of SLM and SEM under the economic spatial weight matrix.

\begin{tabular}{|c|c|c|c|c|c|c|}
\hline & \multicolumn{2}{|c|}{ West China in total } & \multicolumn{2}{|c|}{ Northwest China } & \multicolumn{2}{|c|}{ Southwest China } \\
\hline & SLM model & SEM model & SLM model & SEM model & SLM model & SEM model \\
\hline MechO & $2.0318^{* * *}$ & $2.3588^{* * *}$ & $4.5582^{* *}$ & $9.9815^{* * *}$ & $1.0091^{* *}$ & $0.0824^{* *}$ \\
\hline MechE & $-2.4871^{* *}$ & $-2.9127^{* * *}$ & $-4.6214^{* *}$ & $-5.8742^{* *}$ & $-3.1264^{* * *}$ & $-3.4022^{* *}$ \\
\hline inc & 0.2784 & 0.1819 & -3.0803 & -2.9116 & 1.3902 & 1.0031 \\
\hline gov & -0.2061 & $-0.2731^{*}$ & -0.6158 & -0.5139 & $-1.001^{*}$ & -1.3289 \\
\hline edu & $21.3967^{* * *}$ & $26.3571^{* * *}$ & $21.3682^{* * *}$ & $30.8831^{* * *}$ & $-2.8517^{* *}$ & $-3.1174^{* *}$ \\
\hline tec & $1.8426^{* *}$ & $2.1352^{* * *}$ & $3.3371^{*}$ & $6.8325^{* * *}$ & $2.9113^{* *}$ & $1.3825^{*}$ \\
\hline Spatial error & - & $0.6357^{* * *}$ & - & $0.7932^{* * *}$ & - & $0.5519^{*}$ \\
\hline Spatial lag & 0.4328 & - & $0.5051^{*}$ & - & $0.6352^{* * *}$ & - \\
\hline$R^{2}$ & 0.5371 & 0.6938 & 0.5011 & 0.5862 & 0.5199 & 0.3927 \\
\hline Log likelihood & -47.8317 & -31.9682 & -56.8853 & -45.7751 & -49.3561 & -63.8828 \\
\hline
\end{tabular}

Notes: ${ }^{* * *}, * *$, and ${ }^{*}$ represent the significance levels of $1 \%, 5 \%$, and $10 \%$, respectively.

comparison. As $R^{2}$ and $\log$ likelihood values are higher under SLM than those under SEM (as shown in Table 11), the SLM model is a more appropriate choice under this new matrix.

In consideration of the robustness, the results of two models are displayed at the same time. The agricultural mechanization coefficients in the robustness analysis are statistically significant, being a little lower under the old matrix (as shown in Table 11). Specifically, the coefficients of MechO and MechE in the robustness analysis are broadly in line with the results in Table 8. In other words, the agricultural mechanization operation level has shown a significantly positive effect on agricultural green transformation in the whole west, the northwest, and the southwest in China, whereas the agricultural mechanization equipment level shows opposite effects. With regard to the controlling variables, except for the insignificance of farmers' income (inc) under this new matrix, the other regression results are highly similar to the aforementioned findings.

\section{Conclusions and Policy Recommendations}

This paper, based on panel data from the year 2008 to 2017 in 30 provinces of mainland China, adopts the Malmquist-Luenberger index method to measure the agricultural green transformation level for China, especially western China. Then, the spatial econometric model is used for further empirical investigation on the influence of agricultural mechanization development on the regional agricultural green transformation in western China. Relevant control variables are also considered, and the following four research conclusions are drawn.

Firstly, the agricultural green transformation in western China has made some achievements, showing an upward trend in fluctuations, but the overall green transformation level is still slightly lower than the national average level. Compared with the higher transformation level in the eastern region, the transformation level in the west shows a larger gap and has greater development potential in the future. Secondly, the fluctuating rise trends of both the northwest and southwest are basically consistent with that of the whole western region. However, the average level of agricultural green transformation in southwest China is higher than that in northwest China due to the pull of Chongqing, while the level of agricultural green transformation in northwest China is more balanced and has greater potential for further improvement. Thirdly, the agricultural mechanization operation level in the western region has a positive role in promoting the agricultural green transformation, while the agricultural mechanization equipment level has shown the opposite force, which is basically the same in the northwest, southwest, and the whole west in China. Among them, compared with southwest China, the level of agricultural mechanization in the northwest has a more positive impact on the relatively balanced green transformation in the northwestern region. Fourthly, the improvement of farmers' income and agricultural technology level shows a positive impact on agricultural green transformation in all the western provinces. However, the influence of the agricultural human capital shows regional differentiation, that is, the improvement of farmers' education level can promote the agricultural green transformation in northwest China, while failing to function in southwest China. Local fiscal expenditure on agriculture has no significant impact on the agricultural green transformation.

Therefore, the agricultural green transformation in western China needs to be further promoted. This paper puts forward the following policy recommendations. First of all, the top design from the central government needs to be strengthened and the local governments should enforce. The laws and regulations and standards should be set up to reduce nonpoint source pollution in the process of agricultural production and avoid excessive and inefficient use of various kinds of chemicals such as fertilizers, pesticides, and films. At the same time, China should recycle and use those livestock and poultry manure and crop stalks to make sure the safe and stable agricultural water and soil resources. It must be noted that the western rural economic development level is relatively backward in China, and the central government can qualify the local governments' performance on their agricultural pollution control, to ensure that the local government is not making a single target of GDP growth and putting the task of poverty alleviation above ecological protection [53]. Secondly, the modernization of agriculture in the western region is also inseparable from the support of 
agricultural machines, but in view of the particular geographical conditions and economic level in the western region, it is not suitable for China to solely consider the total power of agricultural machinery as the index of mechanization. The more important thing is to look at the actual operation level of agricultural machinery in agricultural production. To enhance the agricultural mechanization operation level, in the process of developing agricultural mechanization, governments can guide farmers to upgrade old machines with high energy consumption and low efficiency, through policies such as subsidy or tax incentives. The government and enterprises can also help to introduce agricultural machines with big brand and good quality, to decrease multiple-purchase cost and increase operation efficiency for farmers. Finally, in order to strengthen the farmers' awareness on green environmental protection in agricultural production and make them more able to practice green agricultural production, it is necessary to improve the farmers' educational level. Education should be taken seriously to make farmers receive the high school and above level of education. The rural villages should attract more talents to work at home or train the existent rural workers to make them qualified for agricultural sustainable development. China's agricultural green transformation should be driven by active participation of enterprises, farmers, and technicians.

\section{Data Availability}

All data used in this paper are collected from the China Statistical Yearbook, China Rural Statistical Yearbook, China Agricultural Statistical Yearbook, China Environmental Statistical Yearbook, China Energy Statistical Yearbook, China Agricultural Machinery Industry Yearbook, China Science and Technology Statistical Yearbook, China Population and Employment Statistical Yearbook, and Chinese provincial statistical yearbooks, all of which can be found at the following websites: http://www.stats.gov.cn/ tjsj/, https://data.cnki.net/NewHome/Index, and https:// www.chinayearbooks.com.

\section{Conflicts of Interest}

The authors declare that there are no conflicts of interest regarding the publication of this paper.

\section{Acknowledgments}

This research was supported by the National Natural Science Foundation of China (Project no. 71503028) "Study on dynamic incentive system of river basin cross-border compensation and coordinated management based on MLPANT model", the Social Science Planning Project of Chongqing Municipality China (Project no. 2019YBJJ039) "Research on efficient trade cooperation between China and 'Belt and Road' route countries under the international logistics corridor construction," and the Research Project of Sichuan International Studies University Chongqing China (Project no. sisu2019033) "Efficiency measurement and promotion mechanism of interconnection between China and 'Belt and Road' route countries."

\section{References}

[1] F. M. Lu, "The role of agricultural mechanization in the modernization of asian agriculture: Taiwan's experience," Engineering in Agriculture, Environment and Food, vol. 2, no. 4, pp. 124-131, 2009.

[2] C. Q. He and J. Jin, "Challenges and policy suggestions on China's agricultural modernization," Modernization Science Newsletter, vol. 7, no. 4, pp. 3-11, 2017.

[3] M. L. Yang and R. P. Bai, "Research on the imbalance of agricultural mechanization development in China," Transactions of The Chinese Society of Agricultural Machinery, vol. 9, pp. 60-63, 2005.

[4] Q. Tana, T. Atsushi, M. Tsugiyuki, and W. Tao, "Analysis of the spatial variation of soil salinity and its causal factors in China's minqin oasis," Mathematical Problems in Engineering, vol. 2017, Article ID 9745264, 9 pages, 2017.

[5] M. J. Deng, G. C. Xiang, and S. T. Yao, "The effectiveness of the multilateral coalition to develop a green agricultural products market in China based on a TU cooperative game analysis," Sustainability, vol. 10, no. 5, pp. 1-17, 2018.

[6] P. H. Hu and M. Y. Tian, "The green turn of agriculture: its significance and paths," Journal of Southwest Petroleum University, vol. 1, pp. 46-49, 2014, in Chinese.

[7] H. M. Wang, "Supply side reform and China's agricultural green transformation," Macroeconomic Management, vol. 9, pp. 50-54, 2016.

[8] F. W. Yu, "Thinking on agricultural green transformation development in China," Ecological Economy, vol. 4, pp. 42-44+88, 2016.

[9] F. W. Yu, "Study on the eco-compensation policies for the green transformation development of agriculture in China," Ecological Economy, vol. 3, pp. 14-23, 2017.

[10] D. G. Zhao, "Study on the transformation and upgrading of agricultural green development in China," Agricultural Economy, vol. 11, pp. 23-24, 2018.

[11] Q. C. Tan, "Green agriculture as a production mode," China Population, Resources and Environment, vol. 9, pp. 44-51, 2015.

[12] L. Li and X. L. Chen, "On the path of green transformation of agriculture in Fujian under the view of industrial chain," Journal of Fujian Agriculture and Forestry University, vol. 1, pp. 29-33, 2018, in Chinese.

[13] X. Zhang, "The study on agricultural structure optimization and upgrading with green transformation in Enshi," Dissertation paper, Hubei University for Nationalities, Enshi, China, 2014.

[14] L. Li and X. E. Wang, "DEMATEL-based analysis to influencing factors of agricultural greenization-fujian province as a case in point," Journal of Nanjing University of Science and Technology, vol. 2, pp. 50-56, 2018, in Chinese.

[15] X. F. Yan, H. Wang, and J. Huang, "On regional agricultural development and interventional mechanism from green transformation's perspective:based on the analysis of total factor productivity," Science and Technology Management Research, vol. 21, pp. 253-260, 2017.

[16] G. C. Li, N. L. Chen, and R. Min, "Growth and sources of agricultural total factor productivity in China under environmental regulations," China population, Resources and Environment, vol. 11, pp. 153-160, 2011. 
[17] J. Yang and Y. Chen, "Empirical study on China's agricultural production growth under the binding of environment," China population, Resources and Environment, vol. 6, pp. 153-157, 2011.

[18] Q. Wang, H. Wang, and H. D. Chen, "A study on agricultural green TFP in China: 1992-2010,” Economic Review, vol. 5, pp. 24-33, 2012.

[19] D. Pan and R. Y. Ying, "Agricultural total factor productivity growth in China under the binding of resource and environment," Resources Science, vol. 7, pp. 1329-1338, 2013.

[20] F. Gao, "Evolution trend and internal mechanism of regional total factor productivity in Chinese agriculture," The Journal of Quantitative \& Technical Economics, vol. 5, pp. 3-19, 2015.

[21] J. Du, R. Wang, and X. H. Wang, "Environmental total factor productivity and agricultural growth: a two-stage analysis based on DEA-GML index and panel Tobit model," Chinese Rural Economy, vol. 3, pp. 65-81, 2016.

[22] R. Xiao and C. B. Chen, "Can financial support promote agricultural green productivity? An empirical evidence from agricultural chemicals input," Journal of Zhongnan University of Economics and Law, vol. 1, pp. 18-24, 2017, in Chinese.

[23] S. H. Zhang, "The influence of heterogeneous rural human capital on agricultural green total factor productivity: based on provincial panel data in China," Journal of Shanxi University, vol. 5, pp. 127-138, 2017, in Chinese.

[24] C. L. Li, T. F. Fu, and L. Wang, "Study on the measurement of green total factor productivity and its influencing factors in China's agriculture," Journal of Huainan Normal University, vol. 3, pp. 30-36, 2018, in Chinese.

[25] P. F. Ge, S. J. Wang, and X. L. Huang, "Measurement for China's agricultural green TFP," China Population, Resources and Environment, vol. 5, pp. 66-74, 2018.

[26] R. P. Bai, M. L. Yang, and Q. S. Liu, "Study on regional classification of agricultural mechanization development level in China," Chinese Agricultural Mechanization, vol. 3, pp. 24-27, 1999.

[27] Y. L. Zhang, G. Lu, and J. Z. Wu, "The empirical analysis on the influencing factors of agricultural mechanization level based on MIV and GABP neural network model," Research of Agricultural Modernization, vol. 6, pp. 1026-1031, 2015.

[28] Y. S. Yang, P. J. Liu, and N. Li, "Identification and system analysis of the influencing factors on the development of Agricultural Mechanization in Northeast China," Journal of Agrotechnical Economics, vol. 5, pp. 28-33, 2006.

[29] S. L. Lin, W. Ye, and L. H. Zhang, "Is the transfer of rural labor force beneficial to the development of Agricultural Mechanization-based on improved Trans-log Cost Function analysis," Journal of Agrotechnical Economics, vol. 7, pp. 4-17, 2017.

[30] Y. He, "Study on the regional division system of agricultural mechanization development level based on GIS," Transactions of the Chinese Society of Agricultural Engineering, vol. 3, pp. 85-89, 2003.

[31] W. Li, C. X. Xue, R. X. Zhu et al., "Measurement and analysis of regional imbalance of agricultural machinery equipment level in China," Economic Geography, vol. 7, pp. 116-122, 2014.

[32] M. Sheahan and C. B. Barrett, "Ten striking facts about agricultural input use in Sub-Saharan Africa," Food Policy, vol. 67, pp. 12-25, 2017.

[33] C. Liu, M. D. Zhu, and Q. L. Che, "Effects of Agricultural Mechanization on grain production in China: output effect, structure effect and spillover effect," Research of Agricultural Modernization, vol. 4, pp. 591-600, 2018.
[34] K. Ennouri and A. Kallel, "Remote sensing: an advanced technique for crop condition assessment," Mathematical Problems in Engineering, vol. 2019, Article ID 9404565, 8 pages, 2019.

[35] C. Q. Wu and Z. Y. Song, "Study on the measurement and affecting factors of agricultural green total factor productivity in the Yangtze River economic belt," Science \& Technology Progress and Policy, vol. 7, pp. 35-41, 2018.

[36] Y. E. Chen and W. Chen, "Research on the relationship between agricultural mechanization, industrial upgrading and agricultural carbon emission-Based on the empirical analysis of dynamic panel data model," Journal of Agrotechnical Economics, vol. 5, pp. 122-133, 2018.

[37] R. Färe, S. Grosskopf, and C. A. K. Lovell, Production Frontiers, Cambridge University Press, Cambridge, UK, 1st edition, 1994.

[38] B. Li, J. B. Zhang, and H. P. Li, "Temporal and spatial characteristics of agricultural carbon emission in China and decomposition of its influencing factors," China Population, Resources and Environment, vol. 8, pp. 80-86, 2011.

[39] X. M. Guo and S. Huang, "Research on green development efficiency of China's tourism industry under the constraint of carbon emission-Based on the modified Three-stage DEA model," Techno-economics and Management Research, vol. 4, pp. 8-13, 2017.

[40] Y. Chen, "Evaluation and control of agricultural non-point source pollution in Shaanxi province," Dissertation Paper, Northwest A\&F University, Xianyang, China, 2010.

[41] S. Y. Lai, P. F. Du, and J. N. Chen, "Evaluation of non-point source pollution based on unit analysis," Journal of Tsinghua University (SciÆTech), vol. 9, pp. 1184-1187, 2004, in Chinese.

[42] M. P. Chen, J. N. Chen, and S. Y. Lai, "Inventory analysis and spatial distribution of Chinese agricultural and rural pollution," China Environmental Science, vol. 6, pp. 751-755, 2006.

[43] L. T. Liang, "Study on the spatial and temporal characteristics and evolution law of rural ecological environment," Dissertation Paper, Nanjing Agricultural University, Nanjing, China, 2009.

[44] L. Hamelin, M. Borzęcka, M. Kozak, and R. Pudełko, "A spatial approach to bioeconomy: quantifying the residual biomass potential in the eu-27," Renewable and Sustainable Energy Reviews, vol. 100, pp. 127-142, 2019.

[45] Y. H. Chung, R. Färe, and S. Grosskopf, "Productivity and undesirable outputs: a directional distance function approach," Journal of Environmental Management, vol. 51, no. 3, pp. 229-240, 1997.

[46] X. H. Liu, "Analysis of the world macroeconomics situation in 2015 and the perspective in 2016," Review of Economy and Management, vol. 3, pp. 5-13, 2016.

[47] X. K. Zhou, Q. Feng, and R. Liao, "An empirical study on the influencing factors of rural surplus labor transfer," Statistics \& Decision, vol. 16, pp. 74-77, 2010.

[48] F. Luo and H. L. Bao, "Analysis on the relationship between agricultural mechanization and the transfer of rural surplus labor," Hubei Agricultural Sciences, vol. 5, pp. 1263-1266, 2010.

[49] B. F. Lu, W. P. Han, and M. Zhu, "Comparison of evaluation methods of agricultural mechanization development level," Transactions of the Chinese Society of Agricultural Engineering, vol. 16, pp. 46-49, 2015.

[50] Z. C. Yan, Y. B. Qi, and J. Liao, "Comparative analysis of evaluation methods of agricultural mechanization level in China," Journal of Agricultural Mechanization Research, vol. 10, pp. 1-5+74, 2018. 
[51] C. R. Hulten, E. Bennathan, and S. Srinivasan, "Infrastructure, externalities, and economic development: a study of the indian manufacturing industry," The World Bank Economic Review, vol. 20, no. 2, pp. 291-308, 2006.

[52] L. Anselin, R. Florax, and S. J. Rey, Advances in Spatial Econometrics: Methodology, Tools and Applications, SpringerVerlag, Berlin, Germany, 2004.

[53] L. Xu, Z. Zhou, and J. Du, “An evolutionary game model for the multi-agent Co-governance of agricultural non-point source pollution control under intensive management pattern in China," International Journal of Environmental Research and Public Health, vol. 17, no. 7, p. 2472, 2020. 